\title{
The role of the consultant psychiatrist in the clinical team
}

\author{
Tom Harrison, Consultant Psychiatrist, Hollymoor Hospital, Birmingham
}

Many psychiatrists are deeply disturbed by the changing and challenging circumstances in which they are responsible for patient care. This became evident at a conference on the role of the consultant in the clinical team, held by the Health Services Manpower Review at the Royal Society of Medicine on 14 July 1988 and attended by an entirely medical audience. The need for the consultant to act as leader of the clinical team was emphasised without identifying the nature and extent of this task, resulting in the failure to develop any strategy to tackle the many problems identified.

This paper attempts to advance the debate further; first by outlining the issues raised at the conference and then by looking at the wider context of the situation in which psychiatrists find themselves. Attention is drawn to the failure to prepare new consultants for their managerial role and modifications in training are proposed.

\section{The nature and extent of the consultant psychiatrist's role}

\section{Management methods}

Professor Dyson, the conference convenor, outlined four management models: consensus, democracy, anarchy and leadership. Consensus applies to those situations where only unanimous agreement is decisive. Democracy, incorrectly confused with consensus, refers to situations where conclusions are reached by majority agreement; with the outcome being unaffected by dissension. Anarchy is all too common, especially where staff insist on making independent decisions without reference to other workers involved. He considered leadership to be the most usual and preferable approach, which includes a range of styles that others subsume under different designations.

\section{The limitations affecting the consultant role \\ (i) Responsibility for patient care or staff leadership?}

Many speakers failed to distinguish between ultimate responsibility for patient care and leadership of the relevant staff group. Examples that actually highlighted the difference were cited, including that of a doctor who personally gave medication when nursing staff refused to. Yet these were used in a manner that obscured this distinction. Assuming leadership of the staff can be one method of ensuring that patient care is executed satisfactorily, but is not an inevitable consequence.

\section{(ii) Medical or clinical?}

The Royal College of Psychiatrists (1977) states that the consultant has a direct responsibility to coordinate the various disciplines caring for patients to ensure the best treatment of the individual. This, in their view, implies leadership of the team dealing with clinical problems. This argument was well supported at the meeting; but there was uncertainty over whether this entailed medical or clinical leadership.

Medical leadership, confined to diagnosis and pharmacological or physical treatments was considered to be too narrow in scope. Clinical managerial responsibility, which was thought to be more appropriate, was broader in compass; but ill defined.

McKeown (1979) identifies five tasks of clinical medicine: reassurance, treatment of the acute emergency, cure, care and attention. The apparent clarity of this configuration is belied by the inclusion of the less easily definable term 'care', which can be provided by a wide range of health workers. Goldberg (1986), speaking on behalf of the Royal College of Psychiatrists, identified clinical responsibility as belonging to many other professions.

(iii) How far can a particular treatment approach be dictated?

How far the authority of the consultant can extend into forms of care beyond the purely medical is not clear. It is not, for instance, possible to force a member of staff to do psychotherapy and most doctors do not know how to run industrial therapy.

Placement of patients is a particularly contentious issue. Is it appropriate for the consultant to enforce the placement of a particular patient on a ward where the nursing staff are unable to manage that person? How much can medical staff really know how appropriate a particular lodging is, when a patient leaves hospital?

\section{(iv) The effect of environment}

The failure to identify the hospital as part of the community was reiterated. As a result, the distinction between patterns of care provided in single 
institutions or in networks of facilities was obscured. The fact that these two types of provision necessitate different models of staff management was not elaborated.

\section{The relationship of the consultant with other mental health workers}

Marked anxiety was expressed over staff acting independently of the consultant, with instances of how colleagues attempted to subvert patient care being referred to. As a result there was an inappropriate tendency to extrapolate the nature of different professions from the particular actions of some members.

There are two significant aetiological aspects of this. First is the declining morale of the psychiatrist and second are the rising expectations of other mental health workers.

(a) The morale and self-confidence of the psychiatric profession

Sedgwick (1983) delineated many of the circumstances that have undermined the authority of psychiatrists. He noted the failure to accept psychiatric expertise in the legal courts following the Sutcliffe trial, the popularity of anti-psychiatric arguments, the collusion of this attitude with the political 'New Right' as represented by the Government, and the power and credibility achieved by organisations like MIND as expressed through the drafting and amending of the 1983 Mental Health Act.

Psychiatrist authors have continued this theme: in 1987 the Collegiate Trainees' Committee convened a conference to discuss the "apparently poor public image of psychiatry" (Bhugra, 1987). Rawnsley wrote about 'Psychiatry in Jeopardy', Morrison's personal view was of 'Psychiatry in Decline', and Harrington asked if psychiatrists were 'An Endangered Species'.

The attacks on the psychiatric profession continue and the sense of alienation expressed at the conference mirrored this. The need to reaffirm a sense of status was clearly apparent with the four psychiatrists speaking mainly reiterating the need for the consultant to head the clinical team.

\section{(b) The increasing knowledge and expectations of other professionals}

Other professions in mental health have been influenced by a number of factors. These include: a broadening knowledge base and range of skills, increasing specialisation, more graduate nursing recruits, less acceptance of authoritarian management, often accompanied by idealistic enthusiasm, and increasing independence of operation with less direct supervision.
The training of many non-psychiatric disciplines reinforces their criticism of psychiatric practice. Professor Dyson noted this specifically in the new nursing curriculum. Many workers are increasingly operating in relative isolation, using new skills, bringing interest and hope into areas that were previously neglected. This is exemplified by the involvement of psychologists and psychiatric nurses in primary care teams, where they are welcomed with open arms and respect. As a result their opinions alter about the priorities of care and they may react unfavourably to older and less cordial relationships.

Aiding and abetting this potential dissension is the public controversy surrounding mental health issues. It is a reflection of the role of 'madness' and anxieties associated with it, that no other branch of health care has more 'instant experts' in the general population. This leads to some voluntary and political organisations associated with, or influencing the development of, mental health care, being dominated by articulate individuals with strongly antagonistic opinions about the service provided.

This increasing articulateness, assertiveness and expertise, in other professions and associated lay persons, runs concurrent with the crisis in confidence of the psychiatric profession. There is a real threat that the explanation of the latter is sought in the former, rather than looking for more relevant causative factors.

\section{The lack of managerial training for psychiatrists}

The new consultant is often ill prepared for the managerial role expected of him or her. Hardwick (1983), describing his first year in the post, reports that; "more training in networks, and a clearer understanding of the roles of all the other professionals ... would have been desirable". This is the result of two major factors: The nature of the professional training and the neglect of administrative and personnel management skills.

\section{(a) The nature of the professional training}

The emphasis of training for trainees is rightly on academic and practical knowledge of mental ill health. The training schedule is increasingly being refined to achieve this more efficiently. However there are two consequences of this which undermine the individual's ability to work with other professionals. The first is the transitory nature of their attachments. They are rarely able in six or nine months to enter into the network of relationships that exist in a group of people working together, and thus fail to establish an understanding of group interactions and mechanisms. Even where they are able to manage this, there is no supervisory guidance 
regarding their observations. The second is that they fail to experience the long term effect of their actions on the group.

\section{(b) The neglect of administration and personnel management skills}

There are a number of issues to be considered when co-ordinating patient care with a multi-disciplinary staff group. These have been confronted in other areas and expertise in how to resolve the problems has been developed. Management training is provided in some regions; but is often underused and undervalued by psychiatrists. Unfortunately the content of the courses tends to concentrate on management issues outside of the working environment. This is reflected in the available literature, for instance; Management for Clinicians only comments in passing on the clinical team, stating that the consultant has no hierarchical authority.

The 'Criteria for Consultant Posts in Psychiatry' (1986) make no reference to experience of, or training in, these essential skills. There appears to be a dangerous assumption that psychiatrists assimilate them without specific training.

\section{Comment}

The consultant has a major leadership role. However, its extent and exercise is likely to vary according to the environment of, and personalities involved in, any particular practice. Professor Dyson emphasised the need for psychiatrists to ascertain and assert their responsibility in the clinical team. However, the meeting revealed the sense of insecurity facing many individual professionals, their ignorance of the tasks to be faced and the lack of skills acquired to tackle them.

In a field where there are few resources, which is unattractive and unrewarding to many professionals, there needs to be as many "hands to the pump" as possible and their activity effectively coordinated. Fortunately many people of high calibre, commitment and imagination are recruited. They can bring fresh ways of looking at old situations, which may be accompanied by irreverence, attachment to libertarian ideals and strong views untempered by practice. The psychiatrist may be ignorant of much of the knowledge available to these other workers. The letter 'Community Psychiatry!' (Harris, 1987) humorously described the confusion that may result from this. This unfortunately may lead to disparagement of other professionals' expertise. Goldberg (1986) has warned that "those who work only in the environment of their own profession tend to develop the idea that if someone cannot be helped by their own brand of intervention, then they cannot be helped at all".
Watts \& Bennett (1983), discussing management in the interdisciplinary setting, identify six different functions of leadership: structuring of tasks, demonstrating effective involvement with patients, communicating high expectations of other staff and showing confidence that they can be met, articulating a grasp of the goals of the team, providing a broad view of the nature and significance of care and taking responsibilities for relationships to external organisations. These are best assumed by those who have the appropriate skills, rather than investing all of them in one individual. They state that increasing members' contributions to leadership tasks improves the team integration.

These authors indicate the availability of relevant knowledge concerning management within the clinical team. Bringing this information and associated relevant experience to the attention of psychiatrists is perhaps the most neglected area of training. The increasing sense of isolation experienced by the profession may be due to the fact that they have little understanding, apart from an inappropriate reliance on their medical/psychiatric knowledge, of what is happening around them.

\section{Proposals for change}

Training for psychiatrists in administration and personnel management should be improved in two areas. First, the further development of training courses already available and increasing the motivation of psychiatrists to attend them. Second, the experience gained by psychiatric trainees should include acknowledgement of the value they have gained working in therapeutic teams. Particular attachments, such as those in community psychiatry, rehabilitation, psychotherapy and child and adolescent psychiatry, all tend to have a greater dependency on multidisciplinary methods of working. The experience gained in these areas could with benefit be extended beyond the usual six months period now seen as standard, and should specifically include supervision in the interactions occurring between the trainee and the other professions.

To substantiate this, the criteria for consultant posts in psychiatry should include a section on the administrative and personnel managerial qualifications of the applicants for consultant posts.

These proposals are in line with arguments expressed in a number of articles in the Psychiatric Bulletin of the Royal College of Psychiatrists. The recommendations on Training in Social and Community Psychiatry in SHO/Registrar training schemes (1987) states that there should be training in "relationships with other disciplines and services, ... administration and management". The Collegiate Trainees' Committee Working Party Report on the Training Implications of the Shift to Community- 
Orientated Psychiatric Services (1988) emphasised the need for more community based training experience, including "working as a member of a nonhierarchical multi-disciplinary team" and "being an active member of the clinical multi-disciplinary team". It was seen as important by many of those surveyed to gain special training in management skills. This latter point was emphasised by the Working Party on Management Training (1985) and they further emphasised that Consultant Appointments Committees should be asked to evaluate the training experience of applicants.

Enabling future consultants to understand their management role within the network of relationships that make up a clinical team will enable them to act effectively as leaders, where it is relevant, and also to respond to other members' appropriate managerial roles. Learning how to share a common purpose, that of the best possible patient care, leads to an increased sense of cohesion in the team and a sense of self-esteem and worth in every member of that group. Neglect of these issues will lead to increasing disaffection by the other workers and isolation of the psychiatric profession.

\section{References}

BHUGR, D. (1987) The public image of psychiatry. Bulletin of the Royal College of Psychiatrists, 11, 105.

GolDBERG, D. (1986) quoted in BIRLEY, J. L. T. (1987)

Psychiatrists and psychologists: working together for planning services in the post-Griffiths era. Bulletin of the Royal College of Psychiatrists, 11, 211.

HARDWICK, P. (1983) Consultant at large: the first year reviewed. Bulletin of the Royal College of Psychiatrists, 7, 26-28.

HARRIS, V. (1987) Community psychiatry! Bulletin of the Royal College of Psychiatrists, 11, 274-275.

McKrown, T. (1979) In The Role of Medicine, pp. 131-135. Oxford: Blackwell.

Royal College of Psychiatrists (1977) The responsibilities of consultants in psychiatry within the National Health Service. News and Notes, p. 4-7.

(1985) Report of the Working Party on Management Training. Bulletin of the Royal College of Psychiatrists, 9, 84-85.

(1986) Criteria for consultant posts in psychiatry. Bulletin of the Royal College of Psychiatrists, 10,324-325.

-; SECTION fOR SOCIAL AND COMmUNITY PSYCHIATRY (1987) Recommendations on training in social and community psychiatry in SHO/Registrar training schemes. Bulletin of the Royal College of Psychiatrists, 11, 213.

SCOTT, J. \& WEBB, T. (1988) Training implications of the shift to community-orientated psychiatric services, Collegiate Trainees' Committee Working Party Report. Bulletin of the Royal College of Psychiatrists, 12, 151-153.

SEDGWICK, P. (1983) The fate of psychiatry in the new populism. Bulletin of the Royal College of Psychiatrists, 7, 22-25.

WATTS, F. N. \& BENNETT, D. H. (1983) Management of the staff team. In Theory and Practice of Psychiatric Rehabilitation (eds. Watts, F. N. and Bennett, D. H.). Chichester: Wiley.

A full list of references is available from the author on request.

\title{
Befriending: cost-effective community care
}

\author{
D. G. Kingdon, Consultant Psychiatrist; D. TuRkington, Senior Registrar \\ (correspondence); J. Coluss, Development Officer; Department of Psychiatry, \\ Bassetlaw District General Hospital, Worksop, Nottinghamshire; and M. JUDD, \\ Volunteer Coordinator, Bassetlaw MIND
}

In a survey of district plans for Mental Health services (Kingdon, 1988) befriending schemes, where volunteers are recruited to visit isolated and lonely users of psychiatric services, were planned or in existence in 14 of the 127 districts who responded. However, lists of the components of a comprehensive community service (MIND, 1983) and Hirsch
(1988) surprisingly do not include references to such schemes, although Griffiths (1988) alludes to them in his recent report. There are moreover no reports in the psychiatric literature of such enterprises. The scheme established by MIND in Bassetlaw (population $(103,000)$ is therefore described. 